\title{
World Café at Summer School of WHO Collaborating Centre for Epidemiology and Community Dentistry
}

\author{
Rossini, Gisella ${ }^{1, *}$, Concia Valentina ${ }^{1}$, Cagetti Maria Grazia ${ }^{2}$, Campus Guglielmo $^{3}$, Strohmenger Laura $^{2}$ \\ "L. Sacco" Department of Biomedical and Clinical Sciences, University of Milan, Italy \\ ${ }^{2}$ Community Dentistry, University of Milan, Italy \\ ${ }^{3}$ Community Dentistry and Oral Epidemiology Department of Surgery, \\ Microsurgery and Medicine School of Dentistry, University of Sassari, Italy
}

Copyright $\bigcirc 2018$ by authors, all rights reserved. Authors agree that this article remains permanently open access under the terms of the Creative Commons Attribution License 4.0 International License

\begin{abstract}
Objectives of the study: This study is a qualitative evaluation of a teaching method. The 2015 Summer School organized by the WHO Collaborating Centre for Epidemiology and Community Dentistry of Milan took place in Sardinia. The educational objectives of the first day included: make an informal conversation with other members of the summer school; create an interesting exchange of ideas and experiences also between new, "habitué" and beginners with senior professionals of this event; make a group for the works in the next days. Considering the different professional roles, age and context of origin, the purpose of the Pedagogists was to create a positive, relaxed but intimate atmosphere using the pleasure of "informal" conversation, through a creative and practical method: The World Cafè. Materials \& methods: The Pedagogists' first task focused on: caring of the location and the physical setup of the table, creating relevant questions to the concerns of the group, establishing the rules, managing the process to encourage participants to have a non- formal learning experience consequently improving thinking, speaking and listening skills. Finally the participants answered self-administered questionnaire to write about their emotions and cognitive processes that went out during the World Cafè. Results: The analysis of the questionnaires was carried out with Interpretative Phenomenological Analysis (IPA), The interpretative steps identified two emerging themes: "different vs peer" and "discovering vs practicing". Conclusions: The World Café experience improves learning by connection; thinking and learning become dynamic processes instead of learning outcomes.
\end{abstract}

Keywords World Cafè, Learning Environment, Questions that Matter, Cooperative Learning, Dentistry, Dental Hygienist

\section{Introduction}

The WHO Collaborating Centre for Epidemiology and Community Dentistry is located in the Dental Clinic of the Dept. of Science and Health, Hospital San Paolo, in Milan. Since 2006, in the third week of June, The Summer School has taken place in Sardinia, Porto Conte.

In the 5-day course, Italian and International lecturers deal with the main aspects of oral diseases, preventive dentistry, preventive community program and the oral health education.

The course is accessible up to 100 participants, Dentists and Dental Hygienist Lectures are supported by interactive group works and projects, and the group members have the possibility to "experiment" how much they just learned and they can share their opinions and ideas with the speakers and the other members of the groups. The different personal and professional background of the participants makes it difficult to cooperate in the small groups during the following days.

The educational objectives of the first day of the 2015 Summer School included:

- make a nice and informal conversations with different members of the summer school around relevant matters

- create an interesting exchange of ideas and experiences respectively between new and "habitué" of the summer school and between beginners and senior professionals

- encourage participants to contribute their ideas and perspectives

- increase their communication skills and become aware of the adopted strategies

- make a group for the workshops in the following days

This article will examine the use and effectiveness of World Café methodology to create a non-formal learning experience and consequently to facilitate discussions along with interesting exchange of experiences among different participants. 


\section{Materials and Methods}

This study is a qualitative evaluation of a teaching method. It used a World Cafè Methodology to put the participants in a real functional setting, the objectives consisted in working together and at the same time carrying out a reflexive writing on the experience in order to take that experience onto a considerable level of learning awareness.

The World Cafè Methodology is a creative methodology for hosting authentic conversations around questions that matter [2]. It is a method utilised to create collaborative discussions on real life questions [2]. Participants join together at Café style tables where they hold conversations exploring the questions of the Café [3]. At designated time intervals, the participants split up and choose another table they would like to join. Only one participant remains sitting at his own table and becomes the "host table" expert of the previous conversation. This is how this method facilitates the collection of diverse information, cross pollination of ideas and growth of insight [2].

During the 2015 Summer School there were participants $(n o=80)$ included Dentists, Dental Hygienist and university students. All the membership of the 2015 Summer School carried out to World Cafè. Since there was not a room large enough for all the tables, the World Cafè was held in the garden, under the trees and a sunny blue sky. Each table was set up with a large white paper tablecloth, some fruit and a basket of 'pane carasau' (a local kind of bread). Each table hosted 5 to 6 participants, the discussion took place in Italian language and the participants could write their conversations on the tablecloth or put down their own ideas on it while they were having fruit and bread.

The attention was put first on the choice of the location, the disposition and setting up of the tables, modelled after a Cafè.

The next step was briefing on the experience to introduce all the participants to the World Cafè process, setting of the context, sharing the Cafè Etiquette to facilitate the World Cafè process and putting participants at ease.

During the briefing the teachers provided the participants with the following rules for the experience:

1. Pay attention on what to consider important;

2. Share your ideas;

3. Speak from heart and mind;

4. Listen to really understand;

5. Link ideas;

6. Sketch and draw on the tablecloth;

7. they are climates the instructor molds and shapes;

8. Enjoy your time while working.

The participants rotated to a different table every $10-15$ min with most contributors joining five or six tables during the Café. At the beginning they set down with their friends or co-workers, but after few changes they enjoyed meeting new participants, and also they were encouraged to express their concerns and question one another in a face-to-face interaction: the group members have to actually interact in order to cooperate. The concept of the three Café questions was to allow the participants to enter the workshop step by step. They were dentistry and dental hygienists, they came from different part of Italy, they were different professional experts. The proposed questions were conceived to give each participant the possibility to comply with them.

The Cafè questions to the attendees of the 2015 Summer School were:

1) What effects on oral health does the interaction of diverse food lifestyles have in a multicultural environment?

2) How is it possible to motivate a change in people's use of sugar in their eating?

3) Expo 2015 was held under the theme Feeding the Planet, Energy for Life, what kind of connection is there with oral health promotion?

At the end of the Cafè the participants were individually prompted with an understanding and self-care instrument to write about their emotions and cognitive processes that went out during the three- hour lesson of the World Cafè. The questions they had to answer were:

- How did you feel during the World Café experience?

- What did you observe during the table discussions?

- What kind of communication strategies did you use at the table discussions to share ideas?

- What kind of skills do you think you could train during the Café?

- Did you find any difficulties during the Café?

The open-ended self-administered questionnaire was handed out in order to develop a reflexive attitude, interpretative skills and problem solving abilities. The authors $[6,12,13$,$] considered the narration and the writing [1]$ reflection as a useful action for understanding and an instrument to enhance one's own self-care.[4] Each membership of the Summer School answered in a private way, read it alone, and then gave the anonymous reflection writing to the pedagogists.

\section{Results}

The analysis of the questionnaires was carried out with Interpretative Phenomenological Analysis (IPA),[11]. The open-ended self-administered questionnaires were read, divided into meaningful units and assigned a comment to each unit. In the comments of the participants Key words, phrases or explanations were highlighted. Another key of the analysis was the language they used and afterwards the interpretative step was the conceptual annotating.

The test assessment showed that the most participants felt comfortable, curious, relaxed, being in an ideal naturalistic context, interested and involved in the World Café experience[5].

"It was a great experience. I felt involved and I had the possibility to meet and know different people and 


\section{discuss important question of my work"}

Only few participants reported an initial embarrassment and some difficulties in dealing with unknown people, but after a few minutes the "special and informal environment" helped them to overcome their difficulties and feel comfortable.

In the different table discussions, the participants observed and appreciated the possibility of:

- discussing different approaches to questions and problems;

"In the different tables I found something equal and something different, we had the possibility to find new perspectives and have confirmation about our ideas"

- dealing with different ways to express their opinions;

- being open to really listening to each other

- $\quad$ sharing ideas with peer professionals;

"I liked how everyone expresses their ideas: nobody was embarrassed"

- improving their communication skills

- enriching their knowledge through the crosspollination of ideas and the discussions between different tables

\section{"The different ideas and perspectives flowed easily"}

Participants enjoyed moving tables and liked being part of the small groups, where they found it easier to express opinions. The size and shape of the tables was thought to enable discussion and enhance the perception of a 'non-threatening environment'.

Only few participants reported that they had enjoyed a positive experience but stated that some table discussions were repetitive, and some participant even used aggressive and overwhelming ways in the groups. One advantage to moving tables is that no one person dominated the whole event, a fact appreciated by the most participants.

Many participants were able to illustrate the communication strategies that they used in the World Café experience.

The most of them carried Key ideas to new tables, in this way they were able to exchange perspectives and work patterns and they discovered new insights.

\section{"I tried to find shared Keywords to pass down to others tables"}

Other just observed the discussions, reflected about different ideas and perspectives and integrated their opinions and point of views with the others. An important strategy adopted by the participants was listening to each other as the first step to reach a real ability to listen to all ideas and perspectives and try to understand different points of view.

"I trained the ability of complying with the situation, listening others' opinions and enriching my knowledges"
They used proactive communication, tried to create links between different ideas and to put other participants at their ease. Another strategy they explained was writing and drawing on the tablecloth to focus their attention on some central ideas and get a more open minded disposition to the experience.

Moreover the World Café experience was considered by the participant a good method to improve and train some personal and professional skills:

- improving listening and speaking skills;

- training the ability of respecting and paying real attention to other ideas;

- training the ability of adapting to "strange" and uncommon situation;

- enriching yourself by means of adopting different perspectives;

- $\quad$ settling for a real interest in other ways of thinking;

- avoiding the temptation of leading the group;

- practicing the ability of comparison

- practicing reflective skills

- discovering creative skills

- mediating between different ideas

- $\quad$ using tolerance

The interpretative steps identified two emerging themes: "different vs peer" and "discovering vs practicing".

\section{Different vs Peer}

The participants in the self-administered questionnaire often used the word different to mean one's own particular background, learning experience and personal point of view about the situation. The membership of the 2015 Summer School were very different by gender, job experience, age, knowledge, personality etc., therefore there was an initial embarrassment meeting one another. At the beginning the most people usually protect their own identity but it becomes important to learn that it is possible to mix with each other without losing oneself. It also happened during the steps of World Café but after the first round the participants could feel much better than in the beginning, and could sense equity and equality in the experience. They could well enjoy their peer to peer experience and feel themselves meaningful to the others. These emotions thoroughly contributed to build a shared knowledge. Everybody could bring his own interesting contribution in the topic and everybody could learn from each other.

\section{Discovering vs Practicing}

A follow up of the analysis of the self-administered questionnaire on the experience has shown two prevailing movements which have favoured more involvement of the participants into the work. On one hand we can see Action and processes of discovery of new contents. On the other hand we have witnessed both consolidation and practice of the previously learned contents. The attendees in the World 
Cafè - as it was conceived and organized in the 2015 Summer School - could play both the roles of Being and Potential Being, actually living an educational experience thanks to the new self-experience they have carried out.

\section{Discussion}

The role of the pedagogists [7] was to encourage the participants to discover principles for themselves and to construct knowledge by working, answering open-ended questions and solving oral health problems. The first step was to create a positive learning atmosphere by taking care of the physical setting as a facilitator of learning experience; when people feel comfortable to be themselves, they do their most creative thinking, speaking and listening. Universally, cafés are natural places where people meet, know each other, have conversations, or share information and knowledge. This familiar and relaxed environment allows the possibility of useful communication and exploration of possibilities [8].

Moreover the process of educational experience was more attentively handled in the creation of the questions and in the choice of their sequence.

The first question is open and imagines that each person can answer starting from his own professional and non-professional experience.

The second one is also open and provides for that the answers can be about the methodology, so the participants can start to think about something to do. This second step is important because the thinking move from the abstract idea of the first step to the real proposition of the second step. The aim is to have the participant feel involved in a useful process and be a protagonist, and this The attention put on this step by step process will reveal important to create an effective learning environment in the people's mind.

At last the third question is about the future and the possible connection with one's own work. In this case the participants can create a new perspective and can discover a new point of view.

The three steps of the proposal are based on the fact that knowledge is the result of a web of acquaintances acquired from previously established relationships and new relationships, past knowledge and actions taken [9].

The participants can train the networked learning because it is possible to learn from the meeting and the developing of information and knowledge in relation to each other's.

The three themes were discussed by the contributors in informal conversations. At the same time their discussions could be considered fundamentally 'serious', since each one could draw from their own professional experiences and from their own scientific knowledge. Various factors can influence this result, such as the effect of innovation, team cooperation and student cohesiveness in the learning process. When tasks are complex, knowledge, skills, and experiences of group members can be shared so that the collective knowledge of the group can achieve goals otherwise achievable with difficulty. [10]

At the end of the Cafè - after a summing up of their written products on the tablecloths - two near tables would be put together in order [14] to obtain a single more homogeneous group to be working in the following days of the Summer School.

\section{Conclusions}

This experience demonstrates that the choice of how to structure the learning experience influences the personal learning. Choosing such methodology as The World Café that is a cooperative learning method, and a fine, accurate learning environment - and employing it in an adult environment, reveals to be as efficient to discover new learning processes based on the practice of peer-learning and interconnection [9]. So it becomes important to think of the learning environment both as a physical and a mentally stimulating place so that it can easily turn into a satisfactory educational experience.

The participants not only enjoyed the event, but also engaged in 'lively conversations' $[15 ; 16]$ which enhanced the relationships between different members of the Summer School. The purpose of using a café environment as a method of cooperative learning is to create a relaxed but intimate atmosphere that uses the pleasure of conversation to provide a meaningful dialogue in subjects of relevance.

\section{Acknowledgements}

The authors gratefully acknowledge the help and support of the ones who collaborated to the making of the World café and the many individuals who acted as table hosts for the event and migrants participants.

\section{REFERENCES}

[1] Bolton, G. Reflective practice. Writing and professional development. London, Sage Publication, 2005

[2] Broom, Brady, Kecskes, Kildea, 2013, World Cafè Methodology engages stakeholders in designing a Neonatal Intensive Care Unit, Journal of Neonatal Nursing (2013)19, 253-258

[3] Brown J., Isaacs D., The World Cafè - shaping Our Futures Through Conversations That Matter, BK Publisher, San Francisco, 2005

[4] Fieschi L, Matarese M, Vellone E, Alvaro R, De Martinis MG, Medical humanities in healthcare education in Italy: a literature review, Ann Ist Super Sanita. 2013; 49(1):56-64. DOI: 10.4415/ANN_13_01_10.

[5] DE Groot M, Alexander K, Culp B, Keith N. Experiential Learning in Kinesiology: a student perspective, in Pedagogy 
Health Promot. 2015 Sep 1; 1(3):123-133. Epub 2015 Jul 10.

[6] Mann, K., Gordon J., Mac Leod A., Reflection and reflective practice in health professions education: a systematic review. Advance in Health Sciences Education, 14, pp. 595-621, 2009

[7] Mortari L., Apprendere dall'esperienza. Il pensare riflessivo nella formazione. Roma, Carocci, 2003

[8] Pagliarini, R. World Café. Shaping our futures trough conversations that Matter. Journal of Organisational Change Management, Vol 19, Number 2, 2008 pp. 266 -268

[9] E. Morin, Les sept savoirs nécessaires à l'éducation du futur, Paris, UNESCO, 1999

[10] O'Connor, Cotrel - Gibbons, World Café: a proactive approach to working with mentors, Nursing Management. 24, 2, 26-29, 2017

[11] Smith J., Flowers P., Larkin M., Interpretative Phenomenological Analysis: Theory, Method and Research (Inglese) Copertina flessibile use pre-formatted date that complies with legal requirement from media matrix -21 mag
2009

[12] Schon D., The Reflective Practitioner: How Professionals Think In Action2 set. 1984

[13] Zannini L., La valutazione delle pratiche riflessive nella formazione medica: esperienze, metodi, e ruolo delle tecnologie. Educational Reflective Practices. Anno 3/ n. $1 / 2013$

[14] Wen-Long Chang, Shih-Ting Chen, The impact of World Cafè on entrepreneurial strategic planning capability, Journal of Business Research 68 (2015) 1283-1290

[15] Co-Intelligence Institute. 2008. More on the World Café. [WWW document] URLhttp://www.cointelligence.org?P-worldcafe2.html ([accessed 24th January 2008)

[16] People and Participation. 2008. World Café. People and Participation [WWW document]

URLhttp:www.peopleandparticipation.net/pages/veiwpage.ac tion?pageld $=18219161$ (accessed 24th January 2008) 